\section{Going the "Extra" Crop in lean Times}

\author{
E.B. Poling ${ }^{1}$
}

$\mathrm{n}$ these "lean" economic times, many of us are being forced to accept more program assignments as positions are being lost through retirement and, more recently, outright elimination (Cage, 1991). If we evaluate new opportunities in specialty crops through the lens of our existing overburdened and thinly supported extension programs, surely most of these possibilities will be stillborn.

In the case of specialty or nontraditional small fruit crops in the south eastern United States, red raspberries seem to get the most interest and coverage by newspapers and the popular press (Demmer, 1990). In North Carolina, we have numerous "Yankee Transplants" (including myself) who insist on growing "northern" red raspberries that have difficulty in the hot, humid summer climate of the Piedmont and coastal plain. Furthermore, raspberries are especially prone to winter freeze injury in the foothills and mountains of western North Carolina, as temperatures there may fluctuate in January and February by as much as $80 \mathrm{~F}$ in a $24-\mathrm{h}$ period.

There is a growing demand for information pertaining to red raspberry culture in each of North Carolina's major geographic and climatic sections. But, little information derived from a university-directed applied research program in red raspberries exists to extend! With the exception of a recently renewed Rubus breeding program in the Dept. of Horticultural Scienceat the Univ. of North Carolina, efforts in culture and pest control are non-existent.

In this article I address some of the difficultiesextension horticultural specialists face in trying to develop specialty crop production and marketing information.

Information recycling. Recycling leaflets and bulletins from other states with significant commercial red raspberry acreage, such as Oregon and New York, is one approach to satisfying an extension client's demand for information. However, this can be inadequate, and even damaging, if you consider the financial risks to the information-user when so little is known in the region about the basic adaptation of the crop, the pest complex and controls available (if any), and how the market will respond to a new cultivar. Specialty crops such as red raspberries in the southern United States are risky business. Local-

Associate Professor and Extension Specialist (Small Fruits), Department of Horticultural Science, North Carolina State University, Raleigh, NC 27695. ized research is critically needed on disease-resistant cultivars that can tolerate widely fluctuating winter temperatures. However, as N.C. State Univ., like most other land-grant institutions, is being forced to pare applied research programs in small fruit culture and breeding, it is unrealistic to expect a university-based and -directed research program that would address the needs of a small group of specialty crop growers.

Specially crop research is unattracfive. Recycling bulletins is clearly an inferior approach to local testing of cultivars, training systems, and pest management strategies. Assuming that the extension horticulturist had the money and time to direct a new applied research project in a specialty crop, it is an open question whether colleagues in plant pathology or agricultural economics will support the initiative. This matter was addressed at the 1989 ASHS Alternative Crops Colloquium (Estes, 1991) by Extension Economist Estes:

"...economists often view this cooperative work as more 'service' work rather than 'cooperative research.' This perception is pervasive among economists because it is unlikely that reports will result in a journal article."

"The opportunity for economic research (as opposed to cooperating on a horticultural research topic that could use some economic interpretation) must exist before an economist will cooperate on a project."

Faculty, including those with $100 \%$ extension appointments, are, of necessity, highly motivated by projects that will contribute meaningfully to their refereed publication record. Developing a base of practical research and extension information to support a client specialty crop educational program is simply unattractive to our modern-day land-grant professional.

The scientific value of "grower experimentation" questioned. Grower experimentation is the alternative approach I haveadopted for generating information for my red raspberry extension program in North Carolina. I was disappointed to learn that this has not been an effective approach for others. At the 1989 ASHS Colloquium, "Alternative Crops Research and Development Programs-Strategies to Reduce the Plight of the Farmer," it was pointed out by a participant discussing the production of specialty, field-grown cut flowers that: "Unfortunately, with little university-based research, growers have been forced to invest in research programs of their own, leading tounintentional testing redundancy of certain speties. Few growers are properly trained in experimental design and datacollection; therefore, much becomes written about a crop without a scientific basis for the conclusions." (Kelly, 1991).

It is true that growers generally are not trained in experimental design and data collection, but most have powers of observation that are invaluable in identifying significant flaws in new culti- 
vars or production practices introduced by university researchers trained in "experimental design and data collection." Grower experimenters in North Carolina have "willingly" shared with the cooperative extension information they have collected on yields and total income produced for each of the raspberry cultivars we have recommended for trial evaluation. These trials have provided invaluable information to other prospective growers. Through state and county newsletters, videotapes, and regional small fruit workshops, the results are shared with both commercial and non-commercial extension clientele (e.g., master gardeners). Creating new knowledge about red raspberry production is not simply a matter of university researchers "processing" objective information. Rather, it depends on tapping the tacit and often highly subjective insights, intuitions, and hunches of individual growers and making those insights available for testing and use by others.

How many research station reports also provide key information on the market acceptance potential of a new cultivar? How many breeders have the opportunity to cooperate with other faculty in food science and economics, for example, to develop scientific market-based research that would forewarn a breeder's release board of a potential market acceptance problem? The problem is that the university data set is nearly always incomplete. In my view, good interdisciplinary cooperation on applied problems is the best approach to specialty crop research, but such teams fare poorly in our discipline-oriented land-grant university system.

Pitfalls of becoming detached. There can be serious problems with the quality of "grower-directed," on-farm test results, especially when thespecialist has been only tangentially involved. The need for face-to-face communication with the grower is vital. For many growers the interest, support, and empathy of a human adviser enhances inspiration, stimulatescreativity, and isenergizing (Nitsch, 1989). The prolonged absence of a specialist from the testing site sends all the wrong messages to the grower and agent. In contrast, the theory-in-use with many extension administrations is that we need to get away from inefficient face-to-face consultancy with farmers and embrace less-personal "long-distance" telecommunication approaches to extension education and information delivery (Cage, 1991). Before travel budgets of state extension specialists and county agents become completely decimated in our system, I recommend the reading of an interesting report, "Present Trends in European Agricultural Advisory Services" (Nitsch, 1989). Among other things, this empirical study of Swedish farmers shows that computer technologies can supplement, but cannot replace, face-to-face communication in advisory work. The Swedish Videotext has proven effective for the retrieval of information relating to both trivial and well-defined questions, but, as Nitsch states in his report: "For complex decisions, where asking the right question is often of the greatest difficulty, and in situations where the information needs to be interpreted and adapted to one's own conditions; in these instances, face to face consultancy remains indispensable."

Summary. While I see less future prospect for land-grant applied research programs in support of specialty crops, I am encouraged by the resourcefulness and vision of the specialty crop grower. I don't think we should be attaching stigmas to those in extension who seek out growerinnovators as their partners in research. The "Diffusion Research Model" that most of us in the land-grant system follow assumes that all innovations originate at research institutions, whereas many innovations either originate from farmers or are modified by farmers to adapt them better to their situation (Van Den Ben and Hawkins, 1988).

Grower experimentation produces options, opportunities, and learning for the specialist who comes in frequent contact with the specialty crop "practitioner." In turn, I am now allowing myself and my extension program to migrate into a different realm, where grower experimentation is becoming the primary source of innovations and information for my red raspberry client education program in North Carolina. I am becoming considerably less "defensive" and more confident about the prospects for growing red raspberries in the southern United States as I learn from the experiments of these enthusiastic growers. It is a trial and error process. Lots of mistakes are being made, but mistakes lead to changes, new innovations, and economic development. Without mistakes, a specialty crop such as red raspberries in the southern United States will remain just that-a specialty crop!

\section{Literature Cited}

Cage, M.C. 7997. Budget cuts force many states to curb extension programs. Chron of Higher Educ 38(5):1.

Demmer, D. 1990. Raspberries for the Carolinas Carolina Gardener 3(5):18-19.

Testes, EA. 1991. How can the economists and horticulturists cooperate on alternative crop research and development programs? HortScience 26:1138-1140.

Kelly, J. W. 1991. Field production of cut flowers. HortScience 26.1136-1138.

Nitsch, U. 1989. Present trends in European agricultural advisory services. National Symp. on Research in Extension, Columbus, Ohio, 16-18 May 1989.

Vanden Ben, A.W and H.S, Hawkins. 1988. Agricultural extension. Wiley, New York. 